\title{
SinTAGMAS CARDINAIS COMPLEXOS E IMPLICATURAS ESCALARES
}

\section{Complex cardinal noun phrases and scalar implicatures}

\author{
Marcelo Ferreira*
}

\section{INTRODUÇÃo}

De acordo com a abordagem neogriceana para o significado de enunciados contendo numerais, o sentido literal da sentença (1a) é o de que existem três ou mais meninas que foram beijadas pelo João, o mesmo sentido que atribuímos intuitivamente às sentenças em (1b) e (1c) ${ }^{1}$ :
(1) a. João beijou três meninas.
b. João beijou pelo menos três meninas.
c. João beijou mais de duas meninas.

Portanto, de acordo com essa visão, nenhuma dessas três sentenças acarreta (2) abaixo:

(2) João beijou apenas três meninas.

Se isso parece adequado para (1b) e (1c), o mesmo não acontece para (1a), que parece veicular a informação de que o número de meninas beijadas pelo João é exatamente três. A abordagem neogriceana, conforme mostraremos na próxima seção, atribui essa interpretação a fatores pragmáticos, mais especificamente à emergência de uma implicatura conversacional, nas linhas sugeridas por Grice. A questão que se coloca de

\footnotetext{
• Universidade de São Paulo. Durante a elaboração deste artigo, o autor contou com apoio financeiro da FAPESP (processo 05/03140-1)

${ }^{1}$ Do ponto de vista estritamente lógico, (1c) deixa em aberto a possibilidade de que o João tenha beijado algo como duas meninas e meia. Se isto parece absurdo quando o predicado em questão diz respeito a beijar pessoas, o mesmo não aconteceria com comer mais de duas maçãs, por exemplo. Entretanto, conforme ficará claro ao prosseguirmos, tal possibilidade em nada afeta os pontos a serem discutidos neste artigo. Continuarei, portanto, a tratar exemplos do tipo (1b)-(1c) como sinônimos.
} 
imediato é saber por que tal implicatura não emerge no caso de (1b) e (1c), a despeito de serem consideradas equivalentes a (1a).

Buscarei mostrar que se abandonarmos essa abordagem, a não emergência dessas implicaturas pode ser explicada através de fatores independentes de ordem mais geral, relacionados à semântica e à pragmática de perguntas e respostas. O restante do artigo está organizado da seguinte forma: na seção 2, apresento as virtudes da abordagem neogriceana; na seção 3 mostro em detalhes os problemas que os cardinais complexos introduzem ${ }^{2}$; na seção 4 apresento a proposta de Geurts (2006) para o tratamento polissêmico dos numerais; na seção 5 mostro como isso abre as portas para a solução dos problemas colocados pelos cardinais complexos; na seção 6 apresento uma breve conclusão.

\section{A Abordagem NEOGRICEANA}

Sintagmas cardinais como três apartamentos são tipicamente entendidos como exatamente três apartamentos no contexto de uma pergunta (explícita ou implícita) introduzida pela palavra interrogativa quantos, como (3) abaixo:

$$
\text { Quantos apartamentos você tem? }
$$

Assim, se o que está em jogo em certo momento de uma conversa é o número de apartamentos que um dos participantes tem, e se alguém usa a sentença (4) abaixo, tal enunciado será interpretado como afirmando que o número exato de apartamentos possuídos pelo falante é três.

(4) Eu tenho três apartamentos.

Entretanto, sob certas circunstâncias, a leitura exatamente três (ou de maneira mais geral, exatamente $n$ ) desaparece e o que se observa é algo semelhante a pelo menos três (pelo menos $n)^{3}$. Por exemplo, se você sonda um conhecido seu sobre a possibilidade dele ser seu fiador em um contrato de aluguel que estipula a necessidade de que o mesmo tenha (no mínimo) três imóveis em seu nome, uma resposta com (5) não nos compele a inferir que o número de apartamentos do potencial fiador seja igual a três ${ }^{4}$.

(5) Pode ficar tranquilo. Eu tenho três apartamentos em meu nome.

\footnotetext{
${ }^{2}$ Neste artigo chamarei sintagmas da forma Numeral $+N P$ de cardinais simples e sintagmas da forma mais de/pelo menos + Numeral $+N P$ de cardinais complexos.

${ }^{3}$ Cf. Horn (1989, p. 250-251), Levinson (2000, p. 49-54) para discussão e referências.

${ }^{4}$ Talvez a forma mais natural de pronunciar a segunda sentença em (5) seja com um acento focal em tenho.
} 
Note que neste caso, o que está em jogo é uma espécie de requerimento mínimo, sendo que o número exato de apartamentos não parece ser relevante. Há ainda circunstâncias em que o próprio falante alerta sua audiência de que o uso do sintagma cardinal não deve ser associado à interpretação exatamente $n$ :

(6) [Eu sei que] meu fiador tem três apartamentos no nome dele. Eu acho até que ele tem mais.

O que é interessante nesse enunciado é que ele soa coerente, sem gerar um sentimento de contradição. Nesse sentido, há um contraste claro com (7) abaixo:

\# [Eu sei que] meu fiador tem apenas três apartamentos no nome dele. Eu acho até que ele tem mais.

De acordo com a abordagem neogriceana, a qual tem em Larry Horn seu pioneiro, os fatos acima recebem a seguinte explicação, baseada nas máximas de Grice ${ }^{5}$ o sentido literal de um numeral $n$ é pelo menos $n$ ou n ou mais. Assim, ao usar uma sentença como (4), o falante apenas afirma que o número de apartamentos que ele tem é maior ou igual a três, o que deixa em aberto a possibilidade de esse número ser três, quatro, cinco etc. Entretanto, ao interpretá-la, o ouvinte se pergunta por que o falante escolheu essa e não uma das alternativas abaixo:

(8) a. Eu tenho um apartamento.

b. Eu tenho dois apartamentos.

c. Eu tenho quatro apartamentos.

d. Eu tenho cinco apartamentos.

e. (...)

A ideia é que os numerais formam uma escala - chamada escala de Horn - e que o enunciado de uma sentença contendo o membro de uma tal escala deve ser avaliado tendo como pano de fundo um conjunto de alternativas, cada uma delas formada através da substituição do termo escalar por um outro membro da mesma escala. Para cada alternativa A, deve haver uma razão para o falante ter escolhido a sentença que usou e não A.

No caso de (8), para as alternativas (8a) e (8b), a resposta é imediata: elas são acarretadas assimetricamente por (4) e, portanto, são menos informativas que (4). O falante está simplesmente obedecendo às máximas de quantidade de Grice: seja tão informativo quanto puder, desde que a informação fornecida seja confiável e relevante. Mas e quanto às

${ }^{5}$ Cf. Horn (1972), Horn (1989, capítulo 4) e Levinson (2000) para apresentação, discussão e referências. Mas conferir Horn (1992) para uma reavaliação desta abordagem. 
outras alternativas? Estas são mais informativas que (4) e, se assumirmos (como fizemos acima) que elas são relevantes para o tópico em discussão, somos forçados a concluir que o falante ou não dispõe de informação a seu respeito, ou sabe que elas não são verdadeiras. Como é bastante plausível que o falante esteja bem informado a respeito do número de apartamentos que possui, o ouvinte conclui que a razão pela qual as alternativas em (8c), (8d) etc., não foram escolhidas é que elas são falsas. Isso, somado ao fato de que (4) é verdadeira (máxima de qualidade) leva à conclusão de que o que o falante está comunicando é que ele tem três, e somente, três apartamentos ${ }^{6}$.

Já no caso de (5), o que está em jogo é apenas a existência ou não de três apartamentos em nome do falante, sendo irrelevante o número exato de apartamentos possuídos pelo mesmo. Desta forma, dado o sentido literal de (5), nada se pode concluir sobre o número exato de apartamentos que o falante tem, mas apenas que este número é maior ou igual a três.

Por fim, casos como (6) deixam claro uma das principais características das implicaturas conversacionais, a saber, sua cancelabilidade. Em (6), o próprio falante é explícito sobre a possibilidade de o fiador ter mais de três apartamentos, o que é obviamente incompatível com ele acreditar/saber que o mesmo tem apenas três. Como resultado, a implicatura em questão é cancelada, mas sem que o resultado seja percebido como algo contraditório ou inconsistente. Como vimos, isso contrasta com a natureza lógico-semântica da relação de acarretamento. Quando um falante nega algo acarretado por uma sentença previamente usada por ele, ele se contradiz e o resultado é um discurso inconsistente, exatamente como podemos observar em (7).

\section{CARdinAIS COMPLEXos E IMPLICATURAS EsCALARES}

Apesar de bem sucedida nos casos acima, a abordagem neogriceana enfrenta problemas quando confrontada com exemplos contendo modificadores cardinais como pelo menos e mais de:

(9) a. João tem pelo menos três apartamentos.

b. João tem mais de dois apartamentos.

Apesar de tanto (9a) quanto (9b) conterem numerais e terem aparentemente o mesmo sentido literal atribuído pela abordagem neogriceana à sentença (4), nem (9a) nem (9b) veiculam o que (4) veicula, a saber, que João tem três, e não mais do que três, apartamentos. A questão que se

\footnotetext{
${ }^{6}$ Tratamento semelhante tem sido dado ao determinante alguns, frequentemente utilizado como sinônimos de alguns, mas não todos e ao conectivo ou, frequentemente utilizado com interpretação exclusiva, conferindo a sentenças do tipo $p$ ou $q$ o sentido de $p$ ou $q$, mas não ambos. As escalas relevantes nesses casos seriam <alguns, todos $>\mathrm{e}<o u, e>$. Cf. Horn (1989) para discussão detalhada sobre o conceito de escala e sua relevância no cômputo de implicaturas conversacionais.
} 
coloca é justamente por que o uso de numerais nestas sentenças não leva à geração de implicaturas escalares nestes casos. Descritivamente, pelo menos e mais de bloqueiam tal geração e o que se está buscando neste artigo é uma explicação para esse bloqueio ou ausência.

Vejamos o problema mais detalhadamente. Considere, por exemplo, a sentença (9a). De acordo com o que vimos na seção anterior, ela deveria ser avaliada contra o conjunto de alternativas em (10):

(10) a. João tem pelo menos um apartamento.

b. João tem pelo menos dois apartamentos.

c. João tem pelo menos quatro apartamentos.

d. João tem pelo menos cinco apartamentos.

e. (...)

Negando as alternativas mais informativas (neste caso c-e) e efetuando a conjunção do resultado com (9a), chegaremos à conclusão de que João tem exatamente três apartamentos, o mesmo resultado obtido no caso de (4). Procedendo de modo análogo com a sentença em (9b), concluiremos que João tem mais de dois apartamentos, mas não tem mais de três. Isso, é claro, equivale a dizer que o número de apartamentos que o João tem é exatamente três.

Há na literatura algumas tentativas de explicar esses fatos, incluindo os trabalhos pioneiros de Manfred Krifka (1999) e Fred Landman (2000). Essas duas propostas estão inseridas em quadros teóricos diferentes, mas têm um importante aspecto em comum: ambas fazem uso de um mecanismo composicional bidimensional, nas linhas desenvolvidas por Mats Rooth (1985) em sua teoria de associação com foco. Não cabe aqui uma revisão detalhada dessas obras, mas gostaria de ressaltar que apesar de importantes e influentes, os sistemas de Krifka e Landman fazem uso de uma maquinaria ad hoc, em que se postula uma tipologia de valores semânticos alternativos (marcados como negativo, positivo e neutro) e mecanismos especiais sensíveis a essa tipologia, os quais filtram o conteúdo das alternativas e transferem o resultado para o conteúdo proposicional ou assertivo das sentenças. O uso dessa maquinaria um tanto pesada é a meu ver um estímulo à busca de soluções alternativas, e de fato algumas foram propostas recentemente ${ }^{7}$.

Fox e Hackl (2006), por sua vez, sugerem que a escala relevante para se computar implicaturas escalares associadas a numerais são densas, correspondendo não apenas aos números naturais $\langle 1,2,3,4, \ldots\rangle$, como também a uma infinidade de outros números entre eles $<1, \ldots, 2, \ldots, 3, \ldots$, $4, \ldots>$. Tendo isso em mente, considere o que acontece, por exemplo, quando

7 É preciso dizer, entretanto, que parte das complexidades das teorias tanto de Krifka quanto de Landman se devem ao fato de que eles buscam dar conta das chamadas leituras cumulativas envolvendo sintagmas cardinais, um tópico que não menciono no presente artigo, mas que discutas em detalhe em Ferreira (2008). 
um falante faz uso da sentença (9b). Negar as alternativas mais informativas neste caso significa negar todas as alternativas da forma João tem mais de $n$ apartamentos, com $n$ maior que 2 . Mas juntas estas negações contradizem o que o falante havia afirmado através do sentido literal de (9b). Para ver o porquê, considere $a$ como sendo o número de apartamentos do João. Dado o sentido literal de (9b), a deve ser maior que 2 . Como a escala de alternativas é densa, ela conterá um número $b$ maior que 2 e menor que $a$. Isso significa que haverá uma alternativa da forma João tem mais de $b$ apartamentos, sendo que tal alternativa acarreta assimetricamente (9b). Deste modo, surgirá uma implicatura da forma João não tem mais de $b$ apartamentos. Ora, como $b$ é, por hipótese, menor que $a$, se João não tem mais de $b$ apartamentos, então ele não pode ter $a$ apartamentos, o que contradiz o sentido literal de (9b). De acordo com Fox e Hackl, essa é a razão pela qual implicaturas escalares não emergem em exemplos com a expressão mais de n. Entretanto, tal explicação (como os próprios autores reconhecem) não se estende à expressão pelo menos $n$ em casos como (9a). Neste exemplo, as alternativas mais informativas são da forma João tem pelo menos $n$ apartamentos, com $n$ maior que 3 . A negação dessas alternativas não contradiz a asserção, já que João pode ter exatamente três apartamentos. Entretanto, como já salientamos, tanto (9a) quanto (9b) não dão margem à geração de tal implicatura.

Passaremos então a uma linha de ataque diferente. Para tanto, vamos primeiro olhar para uma proposta diferente da neogriceana para os sintagmas cardinais simples.

\section{GeURTS (2006): Numerais E Polissemia}

Parte do apelo conceitual da abordagem neogriceana para o significado dos numerais vem do fato de que a única alternativa que costuma ser vislumbrada é a que considera que esses elementos são ambíguos. Mas a postulação de uma ambiguidade lexical causa sempre desconforto quando os diferentes significados em questão parecem do ponto de vista intuitivo intimamente relacionados e mais ainda quando tal pluralidade de sentidos parece um traço comum a uma diversidade de línguas. Sendo esse o caso dos numerais, não é de se estranhar a extrema simpatia com que a abordagem neogriceana é frequentemente recebida, uma vez que se trata de uma análise estritamente monossêmica, derivando a aparente ambiguidade a partir da interação do sentido literal das expressões em questão com princípios de ordem geral e independentemente motivados que regulam a comunicação humana.

Entretanto, Geurts (2006) chama a atenção para uma terceira visão, a saber, a de que numerais são polissêmicos. Isso quer dizer que eles possuem mais de um significado, mas que estes significados estão relacionados entre si. Conforme ressalta o autor, polissemia é um traço característico do léxico 
das línguas naturais, havendo um número abundante de exemplos, como os abaixo:

(11) a. João bateu a cabeça na porta. [porta = objeto sólido]

b. João atravessou a porta. [porta $=$ abertura]

(12) a. O banco faliu. [banco = instituição financeira]

b. $O$ teto do banco desmoronou. [banco = imóvel]

Assim sendo, uma análise polissêmica para os numerais está imune aos ataques conceituais-metodológicos de que sofrem as análises baseadas em ambiguidade lexical. Obviamente, uma análise polissêmica só adquire valor real quando vai além da mera listagem de casos e fornece mecanismos explícitos para relacionar os diferentes significados em questão. Geurts (2006) se vale de duas regras de mudança de tipos sugeridas por razões independentes no estudo de Partee (1986) no contexto mais amplo da semântica dos sintagmas nominais. A primeira dessas regras transforma um quantificador generalizado em um predicado, enquanto que a segunda opera em sentido inverso, transformando predicados em quantificadores generalizados. Para entender o uso que Geurts faz delas, considere primeiro o fato de que sintagmas cardinais como cinco brasileiros podem ocupar tanto posições argumentais como em (13a-b), quanto posições predicativas, como em (14a-b):

(13) a. Cinco búlgaros chegaram.

b. Maria conhece cinco búlgaros.

(14) a. Os cinco búlgaros chegaram.

b. Aqueles ali são cinco búlgaros.

Geurts assume que o sentido básico de um sintagma cardinal como cinco búlgaros é o de um quantificador generalizado com o significado de exatamente cinco:

(15) Cinco búlgaros chegaram.

$\exists ! X:|X|=5 \&$ bulgaros' $(X) \&$ chegaram' $^{\prime}(\mathrm{X})$

(16) $[[$ cinco búlgaros $]]=\lambda \mathrm{P}: \exists ! \mathrm{X}:|\mathrm{X}|=5 \&$ bulgaros' $^{\prime}(\mathrm{X}) \& \mathrm{P}(\mathrm{X})$

A representação lógica em (15) deve ser lida da seguinte forma: existe um único ( $\exists$ !) grupo de cinco búlgaros tal que seus membros chegaram. Note que isso só será verdadeiro se o número de búlgaros que chegaram for cinco e não mais do que cinco $^{8}$.

\footnotetext{
${ }^{8}$ Se, por exemplo, seis búlgaros $\left(b_{1}-b_{6}\right)$ tiverem chegado, o mesmo poderá ser dito dos grupos de cinco búlgaros $b_{1}-b_{5}$ ou $b_{2}-b_{6}$, entre outros (haverá neste caso seis grupos distintos).
} 
Para dar conta do uso predicativo exemplificado acima, Geurts segue Partee, valendo-se da seguinte regra que deriva uma extensão $\alpha^{\prime}$ de tipo <et> a partir de uma extensão $\alpha^{\prime}$ de tipo <et,t>:

(17) Regra de Mudança de Tipos: $<e t, t>\Rightarrow<e t>$

$$
\alpha_{<\mathrm{et}>}^{\prime}=\lambda \mathrm{z} \cdot \alpha_{<\mathrm{et}, \mathrm{t}>}(\lambda \mathrm{y} \cdot \mathrm{y}=\mathrm{z})
$$

Aplicada à extensão em (16), essa regra resulta no seguinte predicado:

$$
\begin{aligned}
& {[[\text { cinco búlgaros }]]} \\
& =\lambda z .[[\text { cinco búlgaros }]](\lambda y \cdot y=z) \\
& =\lambda z \cdot \exists ! X:|X|=5 \& \text { bulgaros' }(X) \& X=z
\end{aligned}
$$

Note que este predicado só será verdadeiro de grupos constituídos por exatamente cinco búlgaros, e que, portanto, podemos representá-lo como em (19) abaixo:

(19) $[[$ cinco búlgaros $]]=\lambda \mathrm{X} .|\mathrm{X}|=5 \&$ bulgaros' $^{\prime}(\mathrm{X})$

Para obter o significado de cinco búlgaros correspondente a um quantificador generalizado significando algo como pelo menos cinco, Geurts se vale da seguinte regra (também presente em PARTEE, 1986):

$$
\begin{aligned}
& \text { Regra de Mudança de Tipos: }<e t>\Rightarrow<e t, t> \\
& \alpha^{\prime \prime}{ }_{<\mathrm{et}, \mathrm{t}>}=\lambda \mathrm{P} . \exists \mathrm{X}: \alpha_{<\mathrm{et}>}^{\prime}(\mathrm{X}) \& \mathrm{P}(\mathrm{X})
\end{aligned}
$$

Aplicando essa regra ao significado de cinco búlgaros em (19), obteremos:

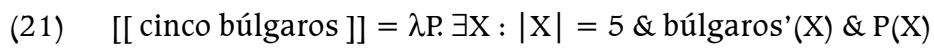

Note que se utilizarmos (21) na derivação do significado da sentença em (13a), obteremos o resultado abaixo:

\section{(22) $\exists X:|X|=5 \&$ búlgaros' $(X) \&$ chegaram’ (X)}

É fácil perceber que a leitura expressa em (22) é a que apenas afirma a existência de um grupo de cinco búlgaros que chegaram, sendo perfeitamente compatível com mais búlgaros tendo chegado.

Concluindo, Geurts oferece uma análise empírica e conceitualmente atraente, de acordo com a qual numerais são polissêmicos. De acordo com essa análise, o sentido literal de sentenças contendo cardinais simples como as que apresentamos acima dependerá da escolha que fizermos para a extensão do sintagma cardinal. Em uma situação concreta, o ouvinte terá 
de se valer de pistas contextuais para inferir qual sentido o falante tinha em mente. Apenas para ilustrar com um caso em que essa polissemia pode causar dúvidas, considere o exemplo abaixo, adaptado de Horn (2005):

(23) Se você acertar duas dessas perguntas, eu te dou cem reais.

Sem maiores informações, ficamos sem saber quem fica com o dinheiro no caso de o João acertar mais de duas questões. Compare isso, com outros casos tradicionalmente analisados como envolvendo implicaturas escalares, como (24) e (25) abaixo:

(24) Se você acertar algumas dessas questões, eu te dou cem reais.

(25) Se você acertar a maioria dessas questões, eu te dou cem reais.

Aqui não parece haver dúvidas: se o ouvinte acertar todas as questões, ele fica com o dinheiro. Contrastes como esse foram apresentados pelo próprio Larry Horn como indicativos de que a abordagem neogriceana não deve ser estendida aos numerais, e que de fato, polissemia parece ser 0 que está em jogo nesse caso.

$\mathrm{Na}$ próxima seção, vamos fazer uso da análise polissêmica de Geurts na análise dos problemas envolvendo cardinais complexos que discutimos nas seções anteriores.

\section{CARdinais Complexos E a PRAgmática das Respostas}

Voltemos agora aos cardinais complexos de que nos ocupávamos anteriormente. Os contextos que nos interessam são aqueles em que o que está em jogo é a cardinalidade de um certo conjunto como o dos carros que o João possui ou o de búlgaros que a Maria conhece. Vamos representar essa questão em discussão concretamente através de uma pergunta introduzida pela palavra quantos:

\section{(26) Quantos búlgaros você conhece?}

Está claro que quando uma pergunta dessas é feita, o que se espera como resposta é o número exato de búlgaros que o ouvinte conhece. Sem entrar em muitos detalhes sobre a semântica de perguntas, vamos representar o significado de (26) da seguinte forma ${ }^{9}$ :

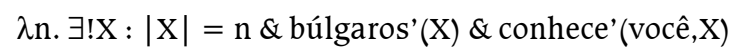

${ }^{9}$ Para apresentações detalhadas (não necessariamente compartilhando com as hipóteses aqui sugeridas) sobre a semântica e a pragmática de perguntas e respostas, cf. Groenendijk e Stokhof (1984, 1997). 
Ou seja, vamos assumir que a denotação de uma pergunta é uma função que leva elementos de um certo domínio (no caso acima números) em proposições. Ao efetuar uma pergunta, o falante solicita ao ouvinte que diga quais elementos são levados a proposições verdadeiras, ou, equivalentemente, quais são as proposições verdadeiras no contradomínio da função. Levando-se em conta a representação acima, respostas esperadas para a pergunta (26) deverão ser ou números $n$ ou proposições como as abaixo:

(28) $\exists ! X:|X|=n$ \& búlgaros' $(X)$ conhece' $(e u, X)$

De acordo com a análise de Geurts que acabamos de apresentar na seção anterior, esse é justamente o significado literal básico de sentenças com a forma abaixo:

\section{(29) Eu conheço $n$ búlgaros.}

Sendo assim, é natural que qualquer resposta diferente dessas sirva de indício de que o falante não está em condições de fornecer um número exato, já que o mesmo se esquivou de dar uma resposta esperada à pergunta em discussão. Podemos formalizar essas considerações partindo das definições em (30)-(33):

(30) Respostas Esperadas

$R$ é uma resposta esperada para uma pergunta $P$ se, e somente se, $\exists \mathrm{x} \in \operatorname{Dom}([[\mathrm{P}]]): R \equiv[[P]](\mathrm{x})$

(31) Respostas Informativas

$R$ é uma resposta informativa para uma pergunta $P$ se, e somente se,

$\exists \mathrm{x} \in \operatorname{Dom}([[\mathrm{P}]]): R \Rightarrow \neg[[P]](\mathrm{x})$

(32) Respostas Completas

$R$ é uma resposta completa para uma pergunta $P$ se, e somente se, $R$ for informativa $\mathrm{e}$

$\forall \mathrm{x} \in \operatorname{Dom}([[\mathrm{P}]]): R \Rightarrow[[P]](\mathrm{x}) \vee R \Rightarrow \neg[[P]](\mathrm{x})$

(33) Respostas Parciais

$R$ é uma resposta parcial para uma pergunta $P$ se, e somente se, $R$ for informativa $\mathrm{e}$

$\neg \forall \mathrm{x} \in \operatorname{Dom}([[\mathrm{P}]]): R \Rightarrow[[P]](\mathrm{x}) \vee R \Rightarrow \neg[[P]](\mathrm{x})$

De uma forma ou de outra, definições como as acima devem fazer parte de uma teoria geral sobre o significado e o uso de perguntas e respostas. O que elas dizem é o seguinte: uma resposta esperada $R$ é uma proposição que pertence à imagem da extensão da pergunta correspondente $P$. Uma 
resposta informativa é uma resposta que acarreta a negação de pelo menos uma das respostas esperadas para $P$. Uma resposta completa é uma resposta relevante que acarreta a negação de todas as respostas esperadas que não são acarretadas por ela. Por fim, uma resposta parcial acarreta a negação de algumas das (mas não todas as) respostas esperadas que não são acarretadas por ela.

Ilustremos então com os casos que nos interessam diretamente:

a. Eu conheço cinco búlgaros.

b. Eu conheço mais de quatro búlgaros.

c. Eu conheço pelo menos cinco búlgaros

A questão em discussão aqui continua sendo (27). Note em primeiro lugar que apenas (34a) é uma resposta esperada, já que nem (34b) nem (34c) são equivalentes a nenhuma proposição da forma eu conheço $n$ búlgaros. Note ainda que todas as respostas acima são informativas já que tomá-las como verdadeiras implica em excluir como falsas respostas esperadas como, por exemplo, eu conheço um/dois/três/quatro búlgaros. Note, por fim, que enquanto (34a) é uma resposta completa à pergunta, excluindo como falsas todas as demais respostas esperadas, (34b) e (34c) são respostas apenas parciais, já que são compatíveis com respostas adequadas que ela não acarreta, como, por exemplo, eu conheço cinco búlgaros e eu conheço seis búlgaros. Essas respostas parciais fornecem apenas valores mínimos para o número de búlgaros conhecidos, sem comprometimento com valores exatos, como se pode ver pelas suas representações semânticas abaixo:

$$
\begin{aligned}
& \text { a. } \exists \mathrm{X}:|\mathrm{X}|>4 \& \text { búlgaros'(X) conhece' (eu,X) } \\
& \text { b. } \exists \mathrm{X}:|\mathrm{X}| \geq 5 \text { \& búlgaros' (X) conhece' (eu,X) }
\end{aligned}
$$

Uma vez concluído que o falante não está em condições de fornecer um número exato, ou seja, uma resposta completa à pergunta a ele dirigida, espera-se, sendo o mesmo um falante cooperativo, que dentre as respostas parciais que ele acredita ser verdadeiras que ele escolha aquela que seja mais informativa. No caso acima, como exemplo de respostas parciais mais informativas que (34b) e (34c), temos (36a) e (36b):

(36) a. Eu conheço mais de cinco búlgaros.

b. Eu conheço pelo menos seis búlgaros

Se o falante preferiu (34b) ou (34c) a (36a) ou (36b), somos levados a crer que ele não está em condições de assegurar a verdade dessas respostas, o que significa que até onde ele sabe, o número de búlgaros conhecido por ele pode ser cinco, como pode ser também maior que cinco. 
Tudo isso parece correto e a meu ver resolve o problema colocado pelos sintagmas cardinais complexos para a abordagem neogriceana para $o$ significado dos numerais. Obviamente, nós abandonamos tal abordagem, mas a explicação final ainda deve ser qualificada de griceana, já que faz uso crucial do contexto de fala e da competição entre alternativas baseada em critérios de veracidade, relevância e informatividade, conforme espero ter ficado claro na discussão que acabamos de realizar. Sobre isso algumas observações se fazem necessárias. Passemos a elas.

Em primeiro lugar, as colocações que fizemos acima sobre a relação entre perguntas e respostas são de natureza geral e não se limitam a sintagmas cardinais e perguntas com quanto. Considere, por exemplo, a pergunta em (37) e as possíveis respostas em (38a)-(38c):

(37) Com quem a Maria está conversando? $\lambda \mathrm{x}$ : conversar' $(\mathrm{m}, \mathrm{x})$

(38) a. Ela esta conversando com o Carlos.

b. Ela está conversando com o Carlos ou com a Ana.

c. Ela está conversando com uma mulher.

Dado o significado de (37), espera-se como resposta algo como ela está conversando $\operatorname{com} x$, em que $x$ é um indivíduo ${ }^{10}$. Assim sendo, (38a) é uma resposta esperada para essa pergunta, ao passo que (38b) e (38c) não. Como consequência, o uso de uma dessas últimas serve de indício de que o falante tem alguma razão para ter se esquivado de fornecer uma resposta esperada, de onde se pode concluir que ele não está em condições de fornecer a identidade da pessoa com quem Maria está conversando ${ }^{11}$.

Note agora que há uma diferença entre o caso acima e o caso anterior envolvendo sintagmas cardinais. Apesar de (38a) ser uma resposta esperada, ela não é uma resposta completa para a pergunta em discussão. Isso porque o fato de Maria estar conversando com Carlos não exclui a possibilidade de ela estar conversando também com outras pessoas, como Pedro, por exemplo. Assim, (38a) nem acarreta nem é incompatível com outras respostas esperadas. Entretanto, diante de uma pergunta como (37), uma resposta com (38a) é interpretada como veiculando a informação de que a Maria está conversando apenas com o Carlos. Para dar conta desse fato, temos de assumir que uma resposta esperada $R$ é interpretada de maneira exaustiva (cf. GROENENDIJK; STOKHOF, 1984), o que significa dizer que $R$ veicula a informação de que todas as demais respostas esperadas (não acarretadas por $R$ ) são falsas ${ }^{12}$.

${ }^{10}$ Incluindo, a princípio, entidades plurais (somas mereológicas à la Link (1983).

${ }_{11}$ Assumindo aqui que não há "pressões" externas para tal esquiva - por exemplo, não se trata de um interrogatório policial - nem motivos para supor que o falante considere irrelevante, ou seja, indiferente à identidade do interlocutor de Maria.

${ }_{12}$ Para discussão e refinamento da noção de exaustividade, ver Fox (2006), Rooij e Schulz (2004), Spector (2007), dentre outros. 
Note que no caso envolvendo cardinais, a interpretação exaustiva de qualquer resposta esperada não terá efeito algum, já que o sentido literal das mesmas já é incompatível com as demais respostas esperadas. E quanto a respostas informativas, porém não esperadas, como as em (38b) e (38c)? Algo nas mesmas linhas deve estar em jogo, já que (38b) passa a ideia de que Maria não está conversando com ninguém que não seja Carlos ou Ana, e (38c) passa a ideia de que Maria não está conversando com nenhum homem.

O ponto crucial a se notar nestes casos é que (38b) e (38c) são equivalentes a disjunções que têm por membros algumas das respostas esperadas para a pergunta em discussão: Maria está conversando com Carlos e Maria está conversando com Ana, no caso de (38b), e todas as respostas do tipo Maria está conversando $\operatorname{com} x$, em que $x$ é uma mulher, no caso de (38c). Essas respostas não devem ser excluídas como falsas, já que isso incorreria em contradição: uma disjunção formada por $n$ termos não pode ser verdadeira se esses $n$ termos são todos falsos. Formulemos, então, o princípio em (39) baseado na definição em (40):

(39) Exaustividade

(i) Se $R$ é uma resposta esperada para uma pergunta cuja extensão é $P$, então interprete $R$ como $\operatorname{Ex}(R)(P)$.

(ii) Se $R$ não é uma resposta esperada para uma pergunta cuja extensão é $P$, e se $R$ é equivalente a uma disjunção de respostas esperadas $R$, então assuma que o falante é ignorante em relação à verdade/ falsidade dos membros de $\mathrm{R}$ e interprete $\mathrm{R}$ como $\operatorname{Ex}(R)(P-R)$.

$$
E x(X)(Y) \equiv X \&[\forall Z \in Y: \neg[X \Rightarrow Z] \rightarrow \neg Z]
$$

Retomemos uma vez mais os casos de respostas parciais com cardinais complexos. Considere (34c) (as mesmas considerações se aplicam a $(34 b))$, repetida abaixo por conveniência:

(41) Eu conheço pelo menos cinco búlgaros.

Esta resposta corresponde à disjunção de todas as respostas esperadas da forma eu conheço $n$ búlgaros $\operatorname{com} n$ maior ou igual a cinco. De acordo com a segunda cláusula do Princípio de Exaustividade, infere-se que o falante é ignorante em relação ao número exato de búlgaros que conhece, sabendo apenas que este número é maior ou igual a cinco. Mas e quanto às respostas esperadas com numerais menores que cinco? Ainda de acordo com o princípio acima, infere-se que estas sejam falsas. Acontece que esta segunda inferência não surte efeito algum, já que a falsidade de tais respostas é uma consequência lógica do sentido literal de (41): se eu conheço cinco ou mais búlgaros, não é possível que o número exato de búlgaros que eu conheço seja menor que cinco. Ficam intactas assim todas as considerações que havíamos feitos anteriormente sobre o uso dos cardinais 
complexos como respostas parciais.

Antes de concluir, gostaria de salientar que ao interpretarmos respostas com os cardinais complexos mais de $n$ ou pelo menos $n$, confrontamos estas respostas com aquelas que fazem uso de um numeral não modificado $n$. A consideração de alternativas com numerais não modificados, entretanto, não foi aleatória. Ao contrário, como já frisado mais acima, a alternativa com o numeral não modificado foi considerada não apenas porque era relevante e mais informativa, mas sobretudo porque era a única forma esperada de responder a pergunta em questão, ao passo que respostas com cardinais complexos eram respostas necessariamente parciais naquele contexto.

Essa observação se faz necessária porque se ao interpretar certo enunciado formos confrontá-lo com todas as alternativas possíveis que sejam relevantes e mais informativas que o próprio enunciado, chegaríamos a resultados indesejados. Considere, por exemplo, o diálogo abaixo, em que o chefe que acaba de chegar ao escritório pergunta a seu secretário sobre os telefonemas recebidos em sua ausência:

$$
\begin{aligned}
& \text { A: Quem telefonou pra mim esta manhã? } \\
& \text { B: O João. }
\end{aligned}
$$

A interpretação natural da resposta de B é que só o João ligou. Podemos chegar a essa interpretação se considerarmos que a decisão do falante em não responder com João e Maria, João e Pedro, João, Pedro e Maria etc. se deve ao fato de as respostas com essas alternativas, apesar de relevantes e mais informativas, não serem verdadeiras (assumindo-se, o que é natural nesse contexto, que B saiba de todo mundo que ligou). Mas se formos levar em consideração alternativas como João mas não Pedro, que também é relevante e mais informativa que a resposta original de $B$, deveríamos concluir que essa alternativa é falsa. Mas se João telefonou é verdadeira (máxima de qualidade) e João mas não Pedro telefonou é falsa (máxima de quantidade), somos forçados a concluir que João E Pedro telefonaram, o que contradiz o resultado de nossa inferência anterior de que só João telefonou.

Após as considerações que fizemos mais acima, temos o que parece uma solução natural para esse dilema. A resposta de B em (42), por ser uma expressão referencial, é (a versão elíptica de) uma resposta esperada à pergunta feita por A. Sendo assim, há apenas que se indagar porque outras respostas igualmente adequadas - como Maria, Pedro, João e Pedro etc. não foram escolhidas por B. Como já dissemos, a razão natural para isso é que tais alternativas sejam falsas e isso está codificado no Princípio de Exaustividade. Nesse contexto, portanto, alternativas como João, mas não Pedro não são levadas em consideração. 


\title{
6 CONCLUSÃO
}

A proposta que defendi aqui está baseada na hipótese de que sempre que uma pergunta (explícita ou implícita) é respondida com uma resposta não esperada e parcial, isso deve ser tomado como indício de que o falante não está em condições de fornecer uma resposta completa para a pergunta em questão. Mostrei que esse será sempre o caso de respostas contendo cardinais complexos como pelo menos 3 carros ou mais de cinco búlgaros no contexto de uma pergunta introduzida pela palavra interrogativa quantos, se abandonarmos a visão neogriceana ortodoxa de que o significado literal de cardinais simples como três carros é, grosso modo, o mesmo de pelo menos três carros. Mostrei, então, como os problemas que estes cardinais complexos apresentavam à abordagem neogriceana desaparecem, sem que outros se coloquem em seu lugar.

\section{RESUMO}

Este artigo discute certos problemas que a interpretação de expressões como mais de dois ou pelo menos três trazem para a abordagem neogriceana do significado de enunciados contendo numerais como dois e três, e propõe uma explicação de ordem semântico-pragmática, diretamente relacionada a aspectos do significado e do uso de perguntas e respostas.

Palavras-chave: numerais; abordagem neogriceana; perguntas.

\begin{abstract}
This article discusses some problems posed by the interpretation of expressions such as more than two and at least three to neogricean approaches to numerals. The proposal has semantics and pragmatic ingredients, which are directly related to the meaning and use of questions and answers.

Keywords: number words; neo-gricean approach; questions.
\end{abstract}

\section{REFERÊNCIAS}

FERREIRA, M. Scope splitting and cumulativity. Ms. Universidade de São Paulo, 2008.

FOX, D. Free choice and the theory of scalar implicatures. Ms. MIT, 2006. 
FOX, D.; HACKL, M. The universal density of measurement. Linguistics and Philosophy n. 29, p. 537-586, 2006.

GEURTS, B. Take five: the meaning and use of a number word. In: VOGELLER, S.; TASMOWSKI, L. (Ed.). Non-definiteness and plurality. Amsterdam/Philadelphia: Benjamins, 2006.

GROENENDIJK, J.; STOKHOF, M. Questions. In: VAN BENTHEN, J.; TER MEULEN, A. (Ed.). Handbook of Logic and Language. Amsterdam: Elsevier, 1997.

Studies on the semantics of questions and the pragmatics of answers. PhD Thesis, University of Amsterdam, 1984.

HORN, L. A Natural History of Negation. Chicago, IL: University of Chicago Press, 1989. . On the Semantic Properties of Logic operators in English. PhD Thesis, UCLA, 1972. The said and the unsaid. In: BARKER, C.; DOWTY, D. (Ed.). SALT II, 1992.

KRIFKA, M. At least some determiners aren't determiners. In: TURNER, K. (Ed.). The Semantics/Pragmatics Interface from Diferent Points of View. Elsevier Science B.V., 1999.

LANDMAN, F. Events and plurality: The Jerusalem Lectures. Dordrecht; Boston: Kluwer Academic Publishers, 2000.

LEVINSON, S. Presumptive Meanings. Cambridge, MA: MIT Press, 2000.

LINK, G. The logical analysis of plurals and mass terms: a lattice-theoretical approach. In: BAUERLE, R.; SCHWARZE, C.; VON STECHOW, A. (Ed.). Meaning, Use and Interpretation of Language. Berlin: de Gruyter, 1983.

PARTEE, B. Noun-phrase interpretation and type-shifting principles. In: GROENENDIJK, J.; DE JONG, D.; STOKHOF, M. (Ed.). Studies in discourse representation theory and the theory of generalized quantifiers. Dordrecht: Reidel, 1986.

ROOIJ, R. Van; SCHULZ, K. Exhaustive interpretation of complex sentences. Journal of Logic, Language and Information, n. 13, p. 491-519, 2004.

ROOTH, M. Association with Focus. PhD Thesis, University of Massachusetts at Amherst, 1985.

SPECTOR, B. Scalar implicatures: Exaustivity and gricean reasoning. In: ALONI, M.; DEKKER, P.; BUTLER, A. (Ed.). Questions in Dynamic Semantics, Emerald Group Publishing, 2007.

Submetido em: 11/09/2008.

Aceito em: 07/07/2009. 